\title{
Effects of plant ingredients with pro-health properties and storage conditions on texture, color and sensory attributes of strawberry (Fragaria $\times$ ananassa Duch.) jam
}

\author{
Anna Korus ${ }^{1 *}$, Anna Banaś1, Jarosław Korus ${ }^{2}$ \\ ${ }^{1}$ Department of Fruit, Vegetable and Mushroom Processing, Faculty of Food Technology, University of Agriculture in Krakow, Krakow, Poland., \\ ${ }^{2}$ Department of Carbohydrate Technology, Faculty of Food Technology, University of Agriculture in Krakow, Krakow, Poland
}

\section{A B S TR A C T}

\begin{abstract}
The following work compares the parameters of texture and color as well as sensory indicators in low-sugar strawberry (Fragaria $\times$ ananassa Duch.) jams both with pro-health plant ingredients (chokeberry, elderberry, Japanese quince, flax seeds, wheat germs and inulin) and without them (control). The products were examined immediately after production and after 6 and 12 months of storage at cold $\left(10^{\circ} \mathrm{C}\right)$ and room temperature $\left(20^{\circ} \mathrm{C}\right)$. Compared with the control jam, the value of gel strength was the highest in the jams with flax seeds and wheat germs, on average by $21 \%$ and $159 \%$, respectively. The investigated ingredients, particularly Japanese quince and elderberry fruit, lowered gel strength by $16 \%$ and $21 \%$, respectively. The ingredients used had an effect on all color parameters and the general sensory evaluation. Adding steviol glycoside and Japanese quince lead to the color of jams being substantially brighter; however, the brightest were the jams with added flax seeds and wheat germs. The addition of chokeberry and elderberry caused significant darkening of the jam. The dominant colors in jams were red and yellow, especially in the jam with added steviol glycoside, Japanese quince and wheat germs. After storage, the value of all texture parameters in jams increased;there were also changes in color, jams were lighter after storage at $20^{\circ} \mathrm{C}$. After a 12-month storage period, the jam with added chokeberry scored the highest $(5.0)$ values, regardless of the storage temperature; the highest scores were also reported for the jam with Japanese quince and inulin stored at $10^{\circ} \mathrm{C}$.
\end{abstract}

Keywords: Jam; Physical properties; Pro-health plant; Sensory properties; Strawberry

\section{INTRODUCTION}

In recent years, there has been a growing consumer demand for functional products. A particularly important role is attributed to constituents with antioxidant properties, which exert antimutagenic and anticarcinogenic effects, prevent aging of the organism and act as free radical scavengers, thereby preventing oxidative stress-induced diseases (Žitňanová et al., 2006).

Fruits, especially berries, are one of the richest sources of vitamins, minerals and health-promoting substances. With a low energy value, they are abundant in vitamin C, polyphenols and organic acids (de Ancos et al., 1999; Šavikin et al., 2009). In view of their seasonal availability and low level of stability, such fruits should undergo processing after harvest, making them available for consumption throughout the year. Of the berry fruits, strawberries enjoy the greatest popularity. These fruits are highly valued due to their sensory properties, especially taste and aroma. Strawberries are also a source of bioactive compounds, including polyphenols, in particular ellagic acid and anthocyanins. These fruits are a valuable raw material for the processing industry; they can be frozen or used in the production of juices, wine, dried products, jellies and jams (Byamukama et al., 2005).

Jams are products which are constantly popular among consumers. They are made from fruits, sugar, citric acid, gelling agents (mainly pectin) and other constituents (EU, 2001). Based on previous studies dealing with quality improvement in jams, much research is focused

\footnotetext{
${ }^{*}$ Corresponding author:

Anna Korus, Department of Fruit, Vegetable and Mushroom Processing, Faculty of Food Technology, University of Agriculture in Krakow, 122 Balicka Street, 30-149 Krakow, Poland. E-mail: rrkorusa@cyf-kr.edu.pl
}

Received: 23 May 2017; Revised: 23 September 2017; Accepted: 27 September 2017; Published Online: 02 October 2017 
on modifications to the raw material composition. Recently, in order to increase the health-promoting value of many traditional and non-traditional food products, the addition of "super fruits" has been promoted, as they offer a high content of antioxidants in the form of polyphenolic compounds and vitamins with antioxidative activity (Wargovich et al., 2012). These are, for example, black chokeberry [Aronia melanocarpa (Michx.) Elliott] and elderberry (Sambucus nigra L.). On the other hand, flax seeds and wheat germs can be valuable ingredients for enriching the fibre content of the products. Inulin, in turn, is used due to both its pro-health and structure-forming properties (Brennan and Tudorica, 2008; Meyer et al., 2011; Peressini and Sensidoni, 2009; Tárrega and Costell, 2006).

The process of jam production leads to the formation of an adequately gelled texture and reduction in water activity; as a result, the product is more stable. Jams are products with a relatively long shelf life (12 months); during storage, however, changes occur in their quality in terms of, color, aroma and taste (García-Martínez et al., 2002). The color of the product plays a very important role because it determines consumer acceptance (Bursać et al., 2007). Texture is also an important quality indicator which markedly affects the acceptability of the product. Hence, sensory analysis of jams combined with the instrumental measurement of color and texture parameters enables more accurate quality assessment of such products (Basu and Shivhare, 2010; Kopjar et al., 2009).

The aim of this research was to evaluate texture and color parameters as well as sensory indicators in low-sugar strawberry jams without plant ingredients and those with the addition of black chokeberry, elderberry, Japanese quince, flax seeds, wheat germs and inulin. The products were assessed immediately after production and after 6 and 12 months of storage at cold temperature $\left(10^{\circ} \mathrm{C}\right)$ and room temperature $\left(20^{\circ} \mathrm{C}\right)$.

\section{MATERIALS AND METHODS}

\section{Materials}

The materials investigated consisted of low-sugar strawberry jams without pro-health ingredients (control) and with the following enriching plant ingredients: black chokeberry [Aronia melanocarpa (Michx.) Elliott], elderberry (Sambucus nigra L.), Japanese quince [Chaenomeles japonica (Thunb.) Lindl. ex Spach], flax seeds (Linum usitatissimum L.), wheat germs (Triticum aestivum L.) and inulin.

The material used to produce the jams was frozen fruits. Immediately after harvest, fully matured fresh fruits were sorted, washed and inedible parts were rejected. Strawberry fruits were frozen as a whole, whereas the fruits of black chokeberry, elderberry and Japanese quince were homogenized before freezing. Flax seeds were ground and defatted (Oleofarm, Wrocław, Poland), while wheat germs were purchased directly from the producer (Sante, Warszawa, Poland). Inulin preparation Orafti ${ }^{\circledR}$ GR (BENEO GmbH, Mannheim, Germany) with a degree of polymerization DP $\geq 10$ was also added to the jams.

Fruit comprised $50 \%$ of the mass of the final product; the refractometric extract of jam was set at 30\% and total acidity at $1 \%$.

For jam production,the following ingredients were also used: sucrose, steviol glycoside (Bio-Nature24, Goerlitz, Germany), as a partial sucrose replacement, citrus-apple pectin (NEDC-A2, Naturex, France) and citric acid (Chem Point, Kraków, Poland).

Steviol glycoside was added to the proportion of $200 \mathrm{mg} \mathrm{kg}^{-1}$ the product (EU, 2011), allowing for partial sucrose replacement and a reduction in the jams' caloric value.

\section{Production of jams}

The following variants of jams were prepared:

S0 - strawberry jam without plant ingredients, sweetened only with sucrose (control),

SS - strawberry jam without plant ingredients, sweetened with sucrose and steviol glycoside,

SCh - strawberry jam with $15 \%$ addition of black chokeberry,

SE - strawberry jam with 15\% addition of elderberry, SJ - strawberry jam with $8 \%$ addition of Japanese quince, SF - strawberry jam with $3 \%$ addition of ground flax seeds, SWG - strawberry jam with 3\% addition of wheat germ, SI - strawberry jam with $10 \%$ addition of inulin.

All the jams with plant ingredients were sweetened with sucrose and steviol glycoside.

Fruits and sweeteners, weighed according to the jam formulation shown in Table 1, were cooked in water in an open pan until the refractometric extract reached about $35 \%$ and the fruit was saturated with sugar $\left(20 \mathrm{~min}, 103^{\circ} \mathrm{C}\right)$. The previously prepared $4 \%(w / v)$ solution of the gelling agent was then added and the whole batch was mixed and cooked for $3 \mathrm{~min}$, finally adding citric acid and mixing again. Next, the jams were bottled in $0.2 \mathrm{~L}$ glass jars, pasteurized at $82-85^{\circ} \mathrm{C}$ for $15 \mathrm{~min}$, and finally cooled to $20 \pm 2^{\circ} \mathrm{C}$.

\section{Storage of jams}

Jams were stored at two temperatures: cold $\left(10^{\circ} \mathrm{C}\right)$ and room $\left(20^{\circ} \mathrm{C}\right)$ until evaluation. Their evaluation was conducted immediately after production and after 6 and 12 months of storage. 
Table 1: Components of strawberry jams $\left(\mathrm{g} \mathrm{kg}^{-1}\right)$

\begin{tabular}{|c|c|c|c|c|c|c|c|c|c|c|c|c|}
\hline \multirow[t]{2}{*}{ Type of jams ${ }^{b}$} & \multicolumn{12}{|c|}{ Ingredients $^{a}$} \\
\hline & $\mathbf{S}$ & Ch & $\mathbf{E}$ & $J$ & $\mathbf{F}$ & WG & $\mathrm{I}$ & Sucrose & Steviol glycoside & Pectin & Citric acid & Water \\
\hline So & 500 & & & & & & & 316 & 0.0 & 11.2 & 5.6 & 167.0 \\
\hline SS & 500 & & & & & & & 258 & 0.2 & 11.2 & 5.6 & 225.0 \\
\hline SCh & 350 & 150 & & & & & & 258 & 0.2 & 11.2 & 5.4 & 225.2 \\
\hline SE & 350 & & 150 & & & & & 260 & 0.2 & 11.2 & 5.0 & 221.4 \\
\hline SJ & 420 & & & 80 & & & & 264 & 0.2 & 11.2 & 3.2 & 221.4 \\
\hline SF & 500 & & & & 30 & & & 256 & 0.2 & 16.0 & 5.6 & 192.0 \\
\hline SWG & 500 & & & & & 30 & & 256 & 0.2 & 16.0 & 5.6 & 192.0 \\
\hline SI & 500 & & & & & & 100 & 176 & 0.2 & 11.2 & 5.6 & 227.0 \\
\hline
\end{tabular}

alngredients: S: Strawberry, Ch: Black chokeberry, E: Elderberry, J: Japanese quince, F: Fax seeds, WG: Wheat germ, I: Inulin, btype of jams: see materials and methods (Production of jams)

\section{Texture analysis}

Jam texture was analyzed according to the procedure described by Genovese et al. (2010) using a TA-XT2plus texturometer (Stable Micro Systems Ltd., Surrey, England). The compressing rate was $2 \mathrm{~mm} / \mathrm{sec}$; the $\mathrm{P} / 20$ probe $(20 \mathrm{~mm}$ in diameter) moved to a penetration depth of $20 \mathrm{~mm}$; and the trigger force was $1 \mathrm{~g}$. The samples were conditioned at room temperature prior to measurements, which for each sample were done in five replications, using five different samples of jam. The following texture parameters were established as texture indicators of the examined jams: $F_{e}(N)$ - gel strength (force at a point in the initial stage of penetration, where little deformation has occurred); $F R(\mathrm{~N})$ - rupture force (the rupture point of the gel); $E(\mathrm{~N} \mathrm{~s})$ - energy of penetration (area under the first pick; $A(\mathrm{~N} \mathrm{~s})$-adhesiveness (area under the negative region of the curve). Based on the parameters $F, F R$ and $E$, one can draw conclusions about the hardness of gel, while parameter A indicates its tendency to adhere to different surfaces. The results obtained were calculated using the Texture Exponent software (Stable Micro Systems Ltd., Surrey, England).

\section{Instrumental color analysis}

The measurement of upper surface color was carried out with the use of Konica Minolta CM-3500d equipment (Konica Minolta Inc., Tokyo, Japan) with reference to illuminant D65 and a visual angle of $10^{\circ}$. The results were expressed using the CIE $\left(L^{*} a^{*} b^{*}\right)$ system (CIE, 2004). On the basis of measurement, the following parameters were set: $L^{*}$ - lightness ( $L^{*}=0$ blackness, $L^{*}=100$ whiteness), $a^{*}$ - the proportion of green $\left(a^{*}<0\right)$ or red $\left(a^{*}>0\right), b^{*}$ - the proportion of blue $\left(b^{*}<0\right)$ or yellow $\left(b^{*}>0\right), C^{*}$ - chroma, and $h^{\circ}$ - hue angle. Each sample was analyzed in five replications. Color differences $\left(\Delta E^{*}\right)$ between samples were calculated according to the equation below:

$\Delta E^{*}=\left[\left(\Delta L^{*}\right)^{2}+\left(\Delta a^{*}\right)^{2}+\left(\Delta b^{*}\right)^{2}\right]^{1 / 2}$

\section{Sensory evaluation}

Sensory evaluation was carried out by using a scoring method with a 5 -score scale, with 1 as the lowest and 5 as the highest grade. With respect to sensory sensitivity, the 15-person panel met the requirements of ISO 3972 (ISO, 1998b) under ISO 6658 (ISO, 1998a) recommended conditions. A standard chart elaborated by the research team was used. For the individual quality factors, the following significance factors were employed: external appearance of the product: surface (syneresis) - 2, structure (disposition of fruit parts in the content of the jam) -3 , color -4 , and consistency -3 , aroma (type and desirability) -4 , taste (type and desirability) -4 . The significance factors were determined on the basis of the opinion of panellists whose experience in sensory evaluation and profound acquaintance with this type of product was acknowledged. The samples, which were stored at $10^{\circ} \mathrm{C}$, were taken out four hours prior to evaluation.

\section{Statistical analysis}

The results concerning the measurement of texture and color parameters were analyzed statistically, using twofactor analysis of variance (first factor - type of jam, second factor - storage), while those concerning the sensory analysis were subjected to one-factor analysis, based on the Snedecor F and Student's t tests (Lin et al., 2017; Matsoukis et al. 2015). The least significant difference (LSD) was calculated at the probability level of $p<0.05$. The Statistica 12.0 (StatSoft, Tulsa, USA) program was applied.

\section{RESULTS AND DISCUSSION}

\section{Texture parameters of strawberry jams}

The jams examined in this research, depending on the plant ingredients used, were characterized by average gel strength ranging within $0.95-3.11 \mathrm{~N}$; the value of the force required to rupture the gel was in the range $1.51-4.20 \mathrm{~N}$ (Table 2). When compared to the control jam (S0), those with added wheat germs and flax seeds exhibited the greatest hardness; their average $F_{e}$ value was higher by $21 \%$ and $159 \%$, respectively. In addition, the FR and $E$ values in these jams were also the greatest. On the other hand, adding Japanese quince and elderberry reduced the strength of the 
Table 2: Changes in gel strength $\left(F_{\mathrm{e}}\right)$, rupture force $(F R)$, energy of penetration $(E)$, and adhesiveness $(A)$ of strawberry jams during storage at different temperatures

\begin{tabular}{|c|c|c|c|c|c|c|c|}
\hline \multirow[t]{2}{*}{ Parameter } & \multirow[t]{2}{*}{ Sample ${ }^{a}$} & \multicolumn{6}{|c|}{ Storage time (months) at $10^{\circ} \mathrm{C}$ and $20^{\circ} \mathrm{C}$} \\
\hline & & 0 & 6 temp. $10^{\circ} \mathrm{C}$ & 6 temp. $20^{\circ} \mathrm{C}$ & 12 temp. $10^{\circ} \mathrm{C}$ & 12 temp. $20 \mathrm{C}$ & Mean \\
\hline \multirow{10}{*}{$F_{\mathrm{e}}(\mathrm{N})$} & So & $1.22 \pm 0.08$ & $1.30 \pm 0.18$ & $1.20 \pm 0.03$ & $1.12 \pm 0.11$ & $1.15 \pm 0.03$ & 1.20 \\
\hline & SS & $1.30 \pm 0.03$ & $1.30 \pm 0.26$ & $1.31 \pm 0.17$ & $1.16 \pm 0.08$ & $1.01 \pm 0.11$ & 1.22 \\
\hline & $\mathrm{SCh}$ & $1.02 \pm 0.10$ & $1.25 \pm 0.09$ & $1.19 \pm 0.05$ & $1.40 \pm 0.15$ & $1.34 \pm 0.07$ & 1.24 \\
\hline & SE & $0.84 \pm 0.11$ & $0.98 \pm 0.06$ & $0.95 \pm 0.08$ & $0.99 \pm 0.22$ & $0.98 \pm 0.21$ & 0.95 \\
\hline & SJ & $0.77 \pm 0.07$ & $1.01 \pm 0.22$ & $0.87 \pm 0.07$ & $1.26 \pm 0.17$ & $1.13 \pm 0.36$ & 1.01 \\
\hline & SF & $2.55 \pm 0.03$ & $3.21 \pm 0.21$ & $2.70 \pm 0.74$ & $3.55 \pm 0.16$ & $3.52 \pm 0.02$ & 3.11 \\
\hline & SWG & $1.21 \pm 0.02$ & $1.46 \pm 0.22$ & $1.45 \pm 0.18$ & $1.60 \pm 0.28$ & $1.52 \pm 0.30$ & 1.45 \\
\hline & SI & $1.07 \pm 0.08$ & $1.30 \pm 0.06$ & $1.21 \pm 0.06$ & $1.04 \pm 0.07$ & $0.95 \pm 0.02$ & 1.11 \\
\hline & Mean & 1.25 & 1.48 & 1.36 & 1.52 & 1.45 & \\
\hline & \multicolumn{7}{|c|}{ LSD $p \leq 0.05^{\mathrm{b}} \mid-0.137, \|-0.109, \mathrm{I} \times \mathrm{\| I}-0.084$} \\
\hline \multirow[t]{10}{*}{$F R(\mathrm{~N})$} & so & $1.49 \pm 0.03$ & $2.12 \pm 0.45$ & $1.59 \pm 0.07$ & $2.07 \pm 0.45$ & $1.54 \pm 0.10$ & 1.76 \\
\hline & SS & $1.65 \pm 0.05$ & $1.92 \pm 0.11$ & $1.86 \pm 0.09$ & $1.84 \pm 0.27$ & $1.80 \pm 0.32$ & 1.81 \\
\hline & $\mathrm{SCh}$ & $1.53 \pm 0.21$ & $2.18 \pm 0.33$ & $1.96 \pm 0.09$ & $2.32 \pm 0.69$ & $1.78 \pm 0.10$ & 1.95 \\
\hline & SE & $1.53 \pm 0.32$ & $1.55 \pm 0.14$ & $1.44 \pm 0.10$ & $1.59 \pm 0.15$ & $1.46 \pm 0.15$ & 1.51 \\
\hline & SJ & $1.26 \pm 0.11$ & $1.62 \pm 0.18$ & $1.50 \pm 0.20$ & $1.90 \pm 0.35$ & $1.80 \pm 0.10$ & 1.62 \\
\hline & SF & $3.77 \pm 0.22$ & $4.75 \pm 0.10$ & $3.78 \pm 0.56$ & $4.45 \pm 0.32$ & $4.25 \pm 0.22$ & 4.20 \\
\hline & SWG & $2.12 \pm 0.46$ & $2.59 \pm 0.20$ & $2.53 \pm 0.17$ & $2.66 \pm 0.17$ & $2.13 \pm 0.09$ & 2.41 \\
\hline & SI & $1.39 \pm 0.16$ & $1.67 \pm 0.13$ & $1.84 \pm 0.37$ & $1.65 \pm 0.35$ & $1.44 \pm 0.27$ & 1.60 \\
\hline & Mean & 1.84 & 2.30 & 2.06 & 2.31 & 2.03 & \\
\hline & \multicolumn{7}{|c|}{ LSD $p \leq 0.05 \mathrm{I}-0.195, \|-0.154, \mathrm{I}$ x $\|-0.435$} \\
\hline \multirow[t]{10}{*}{$E(\mathrm{~N} \mathrm{~s})$} & So & $13.44 \pm 0.78$ & $16.24 \pm 0.87$ & $14.57 \pm 0.93$ & $16.35 \pm 0.36$ & $15.63 \pm 0.74$ & 15.25 \\
\hline & SS & $15.19 \pm 0.15$ & $17.30 \pm 0.53$ & $15.97 \pm 1.15$ & $17.48 \pm 0.31$ & $15.74 \pm 0.36$ & 16.34 \\
\hline & $\mathrm{SCh}$ & $12.79 \pm 0.75$ & $17.92 \pm 1.02$ & $17.02 \pm 0.35$ & $19.80 \pm 0.13$ & $19.17 \pm 1.34$ & 17.34 \\
\hline & SE & $12.78 \pm 0.38$ & $13.43 \pm 1.29$ & $12.65 \pm 0.51$ & $14.76 \pm 0.54$ & $13.76 \pm 1.10$ & 13.48 \\
\hline & SJ & $10.41 \pm 0.90$ & $13.99 \pm 1.66$ & $12.35 \pm 0.57$ & $16.58 \pm 1.16$ & $15.98 \pm 1.04$ & 13.86 \\
\hline & SF & $33.16 \pm 2.18$ & $43.81 \pm 0.56$ & $42.61 \pm 1.63$ & $49.26 \pm 1.66$ & $47.92 \pm 0.75$ & 43.35 \\
\hline & SWG & $17.66 \pm 0.87$ & $23.08 \pm 1.03$ & $19.71 \pm 0.97$ & $24.46 \pm 0.50$ & $21.13 \pm 1.47$ & 21.21 \\
\hline & SI & $12.36 \pm 0.39$ & $15.81 \pm 0.68$ & $15.71 \pm 1.09$ & $14.24 \pm 1.28$ & $12.78 \pm 1.43$ & 14.18 \\
\hline & Mean & 15.97 & 20.20 & 18.82 & 21.62 & 20.26 & \\
\hline & \multicolumn{7}{|c|}{ LSD $p \leq 0.05 \mathrm{I}-0.725, \|-0.574, \mathrm{I}$ x II-1.622 } \\
\hline \multirow[t]{10}{*}{$A(\mathrm{~N} \mathrm{~s})$} & So & $-0.41 \pm 0.03$ & $-0.56 \pm 0.03$ & $-0.53 \pm 0.04$ & $-0.63 \pm 0.03$ & $-0.67 \pm 0.01$ & -0.60 \\
\hline & SS & $-0.47 \pm 0.05$ & $-0.51 \pm 0.03$ & $-0.48 \pm 0.08$ & $-0.56 \pm 0.06$ & $-0.62 \pm 0.03$ & -0.54 \\
\hline & $\mathrm{SCh}$ & $-0.38 \pm 0.02$ & $-0.54 \pm 0.02$ & $-0.56 \pm 0.08$ & $-0.71 \pm 0.06$ & $-0.71 \pm 0.02$ & -0.63 \\
\hline & SE & $-0.36 \pm 0.03$ & $-0.40 \pm 0.03$ & $-0.38 \pm 0.04$ & $-0.40 \pm 0.06$ & $-0.46 \pm 0.04$ & -0.41 \\
\hline & SJ & $-0.37 \pm 0.05$ & $-0.49 \pm 0.08$ & $-0.48 \pm 0.05$ & $-0.72 \pm 0.08$ & $-0.67 \pm 0.03$ & -0.59 \\
\hline & SF & $-1.17 \pm 0.07$ & $-1.53 \pm 0.08$ & $-1.56 \pm 0.08$ & $-2.04 \pm 0.11$ & $-2.12 \pm 0.09$ & -1.81 \\
\hline & SWG & $-0.67 \pm 0.08$ & $-0.92 \pm 0.12$ & $-0.90 \pm 0.05$ & $-0.93 \pm 0.00$ & $-0.92 \pm 0.04$ & -0.92 \\
\hline & SI & $-0.32 \pm 0.04$ & $-0.54 \pm 0.06$ & $-0.62 \pm 0.04$ & $-0.46 \pm 0.08$ & $-0.45 \pm 0.01$ & -0.52 \\
\hline & Mean & -0.52 & -0.69 & -0.69 & -0.81 & -0.83 & \\
\hline & \multicolumn{7}{|c|}{ LSD $p \leq 0.05|-0.042, \|-0.033$,$| x \|-0.094$} \\
\hline
\end{tabular}

Values are presented as mean value $\pm S D(n=5)$, aSample: see materials and methods (production of jams), bLSD $p \leq 0.05$ for: Sample (I), Storage (II), Interaction (I x II)

gel to the greatest extent, by $16 \%$ and $21 \%$, respectively. Furthermore, such jams had the lowest value of rupture force $(F R)$ and energy of penetration $(E)$. Adhesiveness (A) is an important parameter of food quality, since it allows one to predict the degree of adhesion of food onto the teeth (Besbes et al., 2009). An increase in the hardness of the examined jams was generally accompanied by an increase in the $A$ parameter value.

The gel consistency of fruit jams, regarded as one of the factors determining their consumer acceptance, is their characteristic feature (Levaj et al., 2012). In jam production, the primary gelling agent is pectin, which is responsible for its proper consistency. However, the diversity of jam components and their concentrations can lead to changes in gel properties (Gao et al., 2011). Many authors highlight the differences in jam hardness, depending on the fruit species. For example, according to Besbes et al. (2009), date jams were characterized by maximum hardness $(1.40 \mathrm{~N})$, while strawberry jams, cooked traditionally, had a hardness level of $0.62 \mathrm{~N}$, as was reported by Rababah et al. (2011). 
Kopjar et al. (2009) and Rababah et al. (2011) revealed that storage time affected the texture of strawberry jams. Storage of the examined jams affected the level of texture parameters; jams stored at $10^{\circ} \mathrm{C}$ were harder than those kept at $20^{\circ} \mathrm{C}$ (Table 2). This is congruent with the findings of Alves de Oliveira et al. (2015), who noted a statistically significant increase in the hardness of jams during storage. Kopjar et al. (2009) also observed an increase in the values of texture parameters in strawberry jam during storage at room temperature. On the other hand, Suutarinen et al. (2000) reported that strawberry jam firmness was not significantly changed because cross linking between carboxyl groups of adjacent polyuronide chains via calcium ions made the cell wall less accessible to enzymes in the fruit.

\section{Color parameters of strawberry jams}

The average color lightness $\left(L^{*}\right)$ in the examined control jam, sweetened only with sucrose (S0), was 13.94 (Table 3). In comparison with this jam, the addition of inulin, steviol glycoside and Japanese quince resulted in significant brightening, on average by $7 \%, 11 \%$ and $14 \%$, respectively. However, in jams with added flax seeds and wheat germs, which exhibited the highest brightness, the average $L^{*}$ value was found to be markedly higher by $72 \%$ and $79 \%$, respectively. On the other hand, the addition of darkcolored fruits (black chokeberry, elderberry) significantly reduced the $L^{*}$ value, on average by $56 \%(\mathrm{SCh})$ and $37 \%$ $(\mathrm{SE})$, which resulted in jam darkening. During jam storage, there were only slight changes in brightness. Ochoa et al. (1999) have reported that from the point of view of color retention in jams, the most recommended storage temperature is $4^{\circ} \mathrm{C}$.

Color, which attracts consumer attention when choosing a product, is a crucial parameter determining food quality. A red color in strawberry jam is one of the most important quality indicators, which may significantly affect consumer acceptance of such products. In order to determine precisely and objectively the quality of color, an instrumental color measurement can be employed (Ngo et al., 2007).

Table 3: Changes in color parameters $\left(L^{*}, a^{*}, b^{*}\right)$ of strawberry jams during storage at different temperatures

\begin{tabular}{|c|c|c|c|c|c|c|c|}
\hline \multirow[t]{2}{*}{ Parameter } & \multirow[t]{2}{*}{ Sample $^{a}$} & \multicolumn{6}{|c|}{ Storage time (months) at $10^{\circ} \mathrm{C}$ and $20^{\circ} \mathrm{C}$} \\
\hline & & 0 & 6 temp. $10^{\circ} \mathrm{C}$ & 6 temp. $20^{\circ} \mathrm{C}$ & 12 temp. $10^{\circ} \mathrm{C}$ & 12 temp. $20^{\circ} \mathrm{C}$ & Mean \\
\hline \multirow[t]{10}{*}{$L^{*}$} & So & $13.95 \pm 0.29$ & $14.22 \pm 0.55$ & $15.88 \pm 0.11$ & $12.53 \pm 0.32$ & $13.14 \pm 0.26$ & 13.94 \\
\hline & SS & $14.99 \pm 0.73$ & $15.55 \pm 0.71$ & $18.20 \pm 0.09$ & $13.65 \pm 0.29$ & $15.32 \pm 0.65$ & 15.54 \\
\hline & $\mathrm{SCh}$ & $6.90 \pm 0.31$ & $5.24 \pm 0.17$ & $6.82 \pm 0.14$ & $6.06 \pm 0.25$ & $5.60 \pm 0.05$ & 6.12 \\
\hline & SE & $9.16 \pm 0.53$ & $8.27 \pm 0.31$ & $9.24 \pm 0.21$ & $8.51 \pm 0.27$ & $8.88 \pm 0.09$ & 8.81 \\
\hline & SJ & $18.72 \pm 0.53$ & $14.55 \pm 0.66$ & $14.96 \pm 0.47$ & $16.25 \pm 0.24$ & $15.18 \pm 0.84$ & 15.93 \\
\hline & SF & $23.30 \pm 0.35$ & $23.78 \pm 0.15$ & $24.70 \pm 0.49$ & $24.37 \pm 0.14$ & $24.01 \pm 0.57$ & 24.03 \\
\hline & SWG & $23.87 \pm 0.66$ & $25.95 \pm 0.34$ & $24.81 \pm 0.26$ & $25.43 \pm 0.14$ & $24.44 \pm 0.69$ & 24.90 \\
\hline & SI & $14.73 \pm 0.43$ & $14.72 \pm 0.22$ & $17.04 \pm 0.16$ & $12.68 \pm 0.27$ & $15.22 \pm 0.25$ & 14.88 \\
\hline & Mean & 15.70 & 15.28 & 16.46 & 14.90 & 15.22 & \\
\hline & \multicolumn{7}{|c|}{ LSD $p \leq 0.05^{\mathrm{b}} \mid-0.247, \|-0.195, \mathrm{I}$ x II-0.553 } \\
\hline \multirow[t]{10}{*}{$a^{*}$} & So & $22.57 \pm 0.14$ & $19.38 \pm 0.35$ & $15.10 \pm 0.22$ & $16.46 \pm 0.43$ & $14.47 \pm 0.17$ & 17.59 \\
\hline & SS & $24.54 \pm 0.23$ & $19.96 \pm 0.43$ & $15.96 \pm 0.62$ & $17.42 \pm 0.17$ & $14.78 \pm 0.20$ & 18.53 \\
\hline & $\mathrm{SCh}$ & $11.19 \pm 0.62$ & $11.10 \pm 0.36$ & $11.28 \pm 0.20$ & $10.26 \pm 0.20$ & $9.86 \pm 0.09$ & 10.74 \\
\hline & SE & $18.91 \pm 0.50$ & $13.09 \pm 0.07$ & $13.49 \pm 0.33$ & $10.38 \pm 0.23$ & $10.50 \pm 0.40$ & 13.27 \\
\hline & SJ & $25.92 \pm 0.30$ & $19.77 \pm 0.46$ & $18.54 \pm 0.61$ & $17.13 \pm 0.41$ & $16.59 \pm 0.45$ & 19.59 \\
\hline & SF & $22.92 \pm 0.39$ & $14.61 \pm 0.46$ & $13.47 \pm 0.50$ & $14.02 \pm 0.20$ & $13.82 \pm 0.41$ & 15.77 \\
\hline & SWG & $25.95 \pm 0.50$ & $17.75 \pm 0.58$ & $17.18 \pm 0.47$ & $16.63 \pm 0.38$ & $13.93 \pm 0.77$ & 18.29 \\
\hline & SI & $24.68 \pm 0.70$ & $19.24 \pm 0.21$ & $15.98 \pm 0.23$ & $17.47 \pm 0.43$ & $15.67 \pm 0.52$ & 18.61 \\
\hline & Mean & 22.08 & 16.86 & 15.12 & 14.97 & 13.70 & \\
\hline & \multicolumn{7}{|c|}{ LSD $p \leq 0.05 \mathrm{I}-0.256, \|-0.203, \mathrm{I}$ x $\|-0.573$} \\
\hline \multirow[t]{10}{*}{$b^{*}$} & so & $9.54 \pm 0.31$ & $9.64 \pm 0.26$ & $7.26 \pm 0.71$ & $8.33 \pm 0.35$ & $9.28 \pm 0.14$ & 8.81 \\
\hline & SS & $12.10 \pm 0.27$ & $10.14 \pm 0.23$ & $8.47 \pm 0.10$ & $8.92 \pm 0.14$ & $9.51 \pm 0.29$ & 9.83 \\
\hline & $\mathrm{SCh}$ & $1.58 \pm 0.15$ & $1.25 \pm 0.11$ & $0.97 \pm 0.08$ & $1.18 \pm 0.18$ & $1.08 \pm 0.11$ & 1.21 \\
\hline & SE & $5.29 \pm 0.13$ & $5.00 \pm 0.31$ & $4.50 \pm 0.14$ & $4.20 \pm 0.18$ & $4.78 \pm 0.17$ & 4.75 \\
\hline & SJ & $13.06 \pm 0.41$ & $12.81 \pm 0.82$ & $11.22 \pm 0.69$ & $12.24 \pm 0.43$ & $13.03 \pm 0.36$ & 12.47 \\
\hline & SF & $9.12 \pm 0.39$ & $9.07 \pm 0.39$ & $9.84 \pm 0.54$ & $11.30 \pm 0.23$ & $12.10 \pm 0.35$ & 10.29 \\
\hline & SWG & $10.67 \pm 0.40$ & $10.23 \pm 0.21$ & $10.87 \pm 0.18$ & $12.63 \pm 0.26$ & $12.02 \pm 0.83$ & 11.28 \\
\hline & SI & $12.15 \pm 0.43$ & $8.63 \pm 0.52$ & $11.08 \pm 0.39$ & $8.96 \pm 0.50$ & $13.13 \pm 0.32$ & 10.79 \\
\hline & Mean & 9.19 & 8.35 & 8.03 & 8.47 & 9.37 & \\
\hline & \multicolumn{7}{|c|}{ LSD $p \leq 0.05|-0.232, \|-0.184$,$| x II-0.519$} \\
\hline
\end{tabular}

Values are presented as mean value $\pm S D(n=5)$. aSample: see materials and methods (production of jams), 'SD $P \leq 0.05$ for: Sample (I), Storage (II), Interaction (I x II) 
The ingredients used can also have an effect on jam color. Grigelmo-Miguel and Martín-Belloso (1999) showed that the addition of peach fibre to strawberry jam contributed to its brightening and an increase in the proportion of the yellow color. In turn, Kirca et al. (2007) observed a significant darkening of strawberry jam after adding black carrot concentrate. These authors noted that the adding of dark-colored raw materials to the jam may be a good alternative to the coloring of strawberry products, because of the presence of degradation-susceptible anthocyanins in such fruits.

Alves de Oliveira et al. (2015) observed the darkening of jams during storage. According to García-Martínez et al. (2002) and Wicklund et al. (2005), the method of jam storage is one of the factors affecting its color. Patras et al. (2011) and García-Viguera et al. (1999) found that storage temperature had an effect on the color parameters of strawberry jam. The authors mentioned above noted greater color deterioration in jams stored at higher temperature.

The value of the $a^{*}$ parameter in all the evaluated jams was above zero, which indicates the intensity of the red color (Table 3). Compared to the jam coded S0, the products coded SWG, SS, SI and SJ showed significantly higher values of the $a^{*}$ parameter, on average by $4 \%, 5 \%, 6 \%$ and $11 \%$, respectively. However, in the jams with flax seeds, elderberry and black chokeberry, a drop was observed in the proportion of the red color, on average by $10 \%$, $25 \%$ and $39 \%$, respectively. During storage, a reduction was found in the proportion of the red color. It has been proved, however, that the storage of jams at $10^{\circ}$ results in better red color retention compared to storage at $20^{\circ} \mathrm{C}$.

The $b^{*}$ parameter also displayed values higher than zero, which reflects the intensity of the yellow color (Table 3). In the jam coded S0, the average value of the $b^{*}$ parameter was 8.81, while in strawberry jams with added black chokeberry and elderberry it amounted to 1.21 and 4.75 respectively, which means that the proportion of the yellow color was small. In turn, the proportion of the yellow color in the remaining jams was $12-42 \%$ higher than in the jam coded S0. The plant ingredients used therefore had an effect on the value of the $b^{*}$ parameter, i.e. the proportion of the yellow color, which is secondary to the red color in strawberries. During storage, in the majority of jams, the proportion of the yellow color decreased; however, after a year of storage, the value of the $b^{*}$ parameter was higher in most jams stored at $20^{\circ} \mathrm{C}$, compared to those stored at $10^{\circ} \mathrm{C}$. This could be due to anthocyanin degradation (Kirca et al., 2007).

All the evaluated jams had an intense and saturated color $\left(C^{*}\right)$, except those with elderberry and black chokeberry, which were the darkest (Table 4). The $C^{*}$ values in these products were, respectively, $27 \%$ and $45 \%$ lower compared with the jam coded S0. A similar relationship was found with regard to hue angle $\left(b^{\circ}\right)$, which describes the color wheel/cycle, where the values $0^{\circ} / 360^{\circ}$ correspond to the red-purple color; $90^{\circ}$, to the yellow color; $180^{\circ}$, to the green color; and $270^{\circ}$, to the blue color (Kirca et al., 2007). In the jams with added black chokeberry and elderberry, this value was $77 \%$ and $28 \%$ lower, respectively, than in the jam coded S0 which reflected color orientation towards red-purple. This corresponds with the findings of Kirca et al. (2007), who noted lower $b^{\circ}$ values in jams with the addition of black carrot concentrate compared to the samples without such an additive. In addition, during storage, an increase in the $b^{\circ}$ value, in general, was observed; it was greater at higher temperatures. In turn, in this experiment, the samples coded SS, SJ, SF, SWG and SI exhibited higher $b^{\circ}$ values, indicating a shift in color toward yellow, and corresponding well with the higher values of the $b^{*}$ parameter.

Color perception of two samples can be inferred from the color difference $\left(\Delta E^{*}\right)$. Color difference can be interpreted as follows: $0<\Delta E^{*}<1$ - differences in color are unrecognizable to a standard observer; $1<\Delta E^{*}<2$ - only an experienced observer can perceive the difference; $2<\Delta E^{*}<3.5$ - an inexperienced observer is able to perceive the difference; $3.5<\Delta E^{*}<5$ - every observer can easily see the difference; and $\Delta E^{*}>5$ - an observer recognizes two different colors (Mokrzycki and Tatol, 2011; Rogowska, 2015). In comparison with the control jam (S0), jams with plant ingredients showed greater color differences $\left(\Delta E^{*}>5\right)$, hence their color and color of control jam could be perceived as two different colors (Table 4). Only in the case of the jam sweetened with steviol glycoside and inulin the differences in color were smaller $\left(2<\Delta E^{*}<3.5\right)$. However, they were recognizable to the inexperienced observer. The value of the $\Delta E^{*}$ parameter in the jams stored for 12 months at both temperatures $\left(10^{\circ} \mathrm{C}\right.$ and $\left.20^{\circ} \mathrm{C}\right)$ did not differ significantly and were 7.80 and 7.71, respectively (Table 4). However, during a shorter period of storage, the differences found were the result of storage temperature. The value of the $\Delta E^{*}$ parameter in the cold stored jams did not differ significantly to that determined in jams immediately after their production; whereas in jams kept at room temperature, it was significantly lower.

\section{Sensory evaluation}

The sensory quality of the examined jams was very good; in a 5-point scale, final scores ranged from 4.3 to 5.0 points (Table 5). All evaluated jams, regardless of the kind of plant ingredients and the storage period, had a proper surface without showing any symptoms of syneresis. Fruits were evenly distributed throughout the mass of 
Table 4: Changes in chroma $\left(C^{*}\right)$, hue angle $\left(h^{9}\right)$, and color difference $\left(\Delta E^{*}\right)$ of strawberry jams during storage at different temperatures

\begin{tabular}{|c|c|c|c|c|c|c|c|}
\hline \multirow[t]{2}{*}{ Parameter } & \multirow[t]{2}{*}{ Sample $^{a}$} & \multicolumn{6}{|c|}{ Storage time (months) at $10^{\circ} \mathrm{C}$ and $20^{\circ} \mathrm{C}$} \\
\hline & & 0 & 6 temp. $10^{\circ} \mathrm{C}$ & 6 temp. $20^{\circ} \mathrm{C}$ & 12 temp. $10^{\circ} \mathrm{C}$ & 12 temp. $20^{\circ} \mathrm{C}$ & Mean \\
\hline \multirow[t]{10}{*}{$C^{*}$} & So & $24.54 \pm 0.07$ & $21.76 \pm 0.37$ & $16.97 \pm 0.28$ & $16.90 \pm 0.33$ & $17.19 \pm 0.24$ & 19.47 \\
\hline & SS & $27.29 \pm 0.37$ & $21.58 \pm 0.46$ & $18.07 \pm 0.59$ & $16.93 \pm 0.23$ & $17.50 \pm 0.34$ & 20.27 \\
\hline & $\mathrm{SCh}$ & $11.25 \pm 0.62$ & $11.08 \pm 0.34$ & $11.29 \pm 0.20$ & $10.37 \pm 0.19$ & $9.92 \pm 0.07$ & 10.78 \\
\hline & SE & $19.55 \pm 0.54$ & $14.32 \pm 0.40$ & $14.20 \pm 0.36$ & $11.25 \pm 0.24$ & $11.67 \pm 0.42$ & 14.20 \\
\hline & SJ & $29.14 \pm 0.51$ & $21.22 \pm 0.69$ & $22.19 \pm 0.25$ & $20.95 \pm 0.53$ & $21.07 \pm 0.45$ & 22.91 \\
\hline & SF & $24.52 \pm 0.65$ & $16.99 \pm 0.41$ & $16.73 \pm 0.51$ & $17.99 \pm 0.30$ & $18.27 \pm 0.58$ & 18.90 \\
\hline & SWG & $28.00 \pm 0.62$ & $20.25 \pm 0.70$ & $20.21 \pm 0.52$ & $20.83 \pm 0.48$ & $18.88 \pm 0.49$ & 21.63 \\
\hline & SI & $27.93 \pm 0.49$ & $19.33 \pm 0.33$ & $19.35 \pm 0.15$ & $15.57 \pm 0.66$ & $20.34 \pm 0.59$ & 20.50 \\
\hline & Mean & 24.03 & 18.32 & 17.38 & 16.35 & 16.85 & \\
\hline & \multicolumn{7}{|c|}{ LSD $p \leq 0.05^{\mathrm{b}} \mathrm{I}-0.280, \|-0.221, \mathrm{I} \times \mathrm{\|}-0.625$} \\
\hline \multirow[t]{10}{*}{$h^{\circ}$} & so & $23.24 \pm 0.56$ & $26.64 \pm 0.55$ & $26.36 \pm 0.30$ & $29.91 \pm 0.34$ & $32.49 \pm 0.59$ & 27.73 \\
\hline & SS & $26.12 \pm 0.40$ & $28.16 \pm 0.24$ & $27.98 \pm 0.67$ & $31.65 \pm 0.11$ & $33.01 \pm 0.47$ & 29.38 \\
\hline & $\mathrm{SCh}$ & $8.01 \pm 0.29$ & $6.17 \pm 0.38$ & $4.69 \pm 0.23$ & $6.66 \pm 0.67$ & $6.09 \pm 0.62$ & 6.32 \\
\hline & SE & $15.51 \pm 0.43$ & $19.71 \pm 0.40$ & $18.54 \pm 0.21$ & $21.79 \pm 0.79$ & $24.27 \pm 0.10$ & 19.96 \\
\hline & SJ & $26.70 \pm 0.46$ & $26.65 \pm 0.40$ & $31.83 \pm 0.48$ & $35.13 \pm 0.19$ & $38.30 \pm 0.81$ & 31.72 \\
\hline & SF & $22.05 \pm 0.49$ & $33.38 \pm 0.47$ & $37.59 \pm 0.63$ & $38.73 \pm 0.49$ & $41.36 \pm 0.20$ & 34.62 \\
\hline & SWG & $22.37 \pm 0.51$ & $32.34 \pm 0.33$ & $32.17 \pm 0.38$ & $37.25 \pm 0.16$ & $40.85 \pm 0.33$ & 32.99 \\
\hline & SI & $27.64 \pm 0.69$ & $29.68 \pm 0.71$ & $35.30 \pm 0.69$ & $34.47 \pm 0.63$ & $39.73 \pm 0.41$ & 33.36 \\
\hline & Mean & 21.45 & 25.34 & 26.81 & 29.45 & 32.01 & \\
\hline & \multicolumn{7}{|c|}{ LSD $p \leq 0.05|-0.301, \|-0.238$,$| x II-0.674$} \\
\hline \multirow[t]{10}{*}{$\Delta E^{*}$} & \multicolumn{7}{|c|}{ so } \\
\hline & SS & $3.49 \pm 0.41$ & $1.69 \pm 0.76$ & $2.82 \pm 0.26$ & $1.85 \pm 0.15$ & $2.23 \pm 0.44$ & 2.42 \\
\hline & $\mathrm{SCh}$ & $15.58 \pm 0.53$ & $14.84 \pm 0.27$ & $11.69 \pm 0.35$ & $11.47 \pm 0.19$ & $12.07 \pm 0.13$ & 13.13 \\
\hline & SE & $7.41 \pm 0.14$ & $9.85 \pm 0.45$ & $7.40 \pm 0.50$ & $8.39 \pm 0.45$ & $7.37 \pm 0.36$ & 8.08 \\
\hline & SJ & $6.82 \pm 0.32$ & $5.90 \pm 0.46$ & $5.85 \pm 0.79$ & $5.50 \pm 0.26$ & $4.79 \pm 0.67$ & 5.77 \\
\hline & SF & $9.38 \pm 0.53$ & $10.71 \pm 0.78$ & $9.36 \pm 0.48$ & $12.46 \pm 0.22$ & $11.24 \pm 0.14$ & 10.63 \\
\hline & SWG & $10.42 \pm 0.53$ & $11.87 \pm 0.28$ & $9.88 \pm 0.55$ & $13.60 \pm 0.22$ & $11.67 \pm 0.23$ & 11.49 \\
\hline & SI & $3.48 \pm 0.69$ & $1.34 \pm 0.24$ & $4.10 \pm 0.48$ & $1.36 \pm 0.34$ & $4.59 \pm 0.20$ & 2.97 \\
\hline & Mean & 8.08 & 8.03 & 7.30 & 7.80 & 7.71 & \\
\hline & \multicolumn{7}{|c|}{ LSD $p \leq 0.05$ I-0.339, II-0.286, I x II-0.758 } \\
\hline
\end{tabular}

Values are presented as mean value \pm SD $(n=5)$. aSample: see materials and methods (production of jams), bSD $p \leq 0.05$ for: Sample (I), Storage (II), Interaction (I x II)

the product. The jams were characterized by lubricant consistency, appropriate for this group of products. The color of the jams, particularly those with added black chokeberry, elderberry and Japanese quince, scored high values, while the addition of wheat germs and flax seeds had a detrimental effect on this indicator, which after a year of storage scored 3.0 to 3.3 points, respectively. The taste of jams scored very high values, except the jam with added wheat germs, which after a 12-month of period storage deteriorated and scored 3.6 points.

The sensory properties of food products are extremely important, both for consumers and producers of food, since they relate directly to the product's quality and consumer acceptance (Barrett et al., 2010; Bursać et al., 2007). Therefore, even the smallest change in the product should be investigated for sensory perception (Javanmard et al., 2012). The final quality assessment of the product is based on such sensory indicators as color, appearance, aroma, taste and consistency (Basu and Shivhare, 2010).
The sensory features of jams can be affected by their components, particularly the variety of fruit and even the stage of its maturity (Gao et al., 2011; Levaj et al., 2012). Halat et al. (1997) noted that the method of fruit harvesting may also have an effect on jam quality. Jams made from hand-picked blackberries were more intense in flavor than those obtained from machine-harvested fruits (Halat et al., 1997). In turn, Kmiecik et al. (2001) reported that the addition of chokeberry syrup to raspberry and strawberry jams had a beneficial effect on their aroma and taste. Grigelmo-Miguel and Martín-Belloso (1999) observed that adding higher doses of peach fibre to strawberry jams led to color darkening in these products. Kucharska et al. (2010) evaluated highly the color of pumpkin puree with the addition of chokeberry, while adding strawberries resulted in better taste and consistency of the product. In the present work, in most cases there were no significant differences in the general sensory evaluation between fresh and stored jams; a substantial worsening was found only in the jams with added wheat 
ज

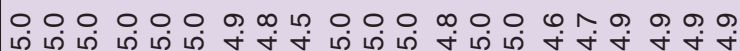

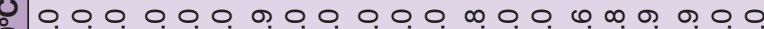
|

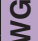

ம ம் ம்

이 우

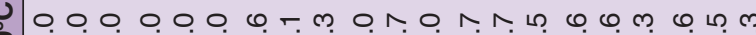

山

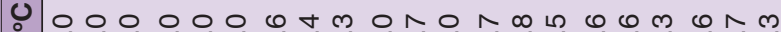
()

ம

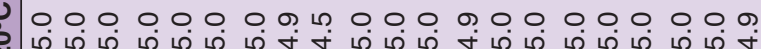

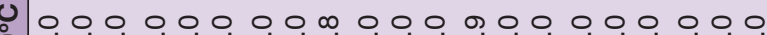

ம

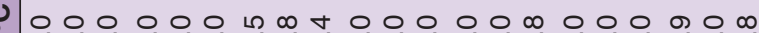

山

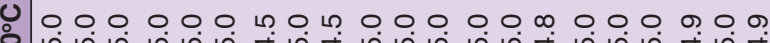

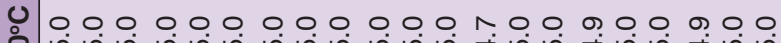

든

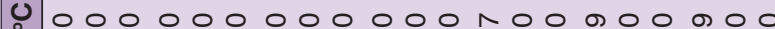

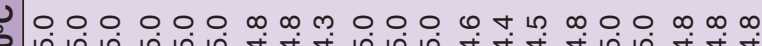

क

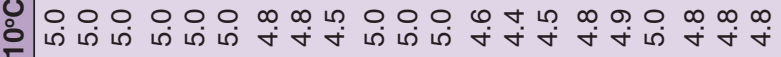

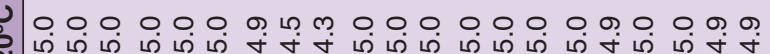

के

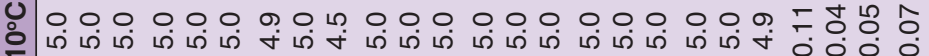

를

$00 \cong 00 \cong 00 \cong 00 \cong 00 \cong 00 \cong 00 \cong 00 \cong$

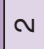

m

$\nabla$

$\checkmark$

$\checkmark$

ล

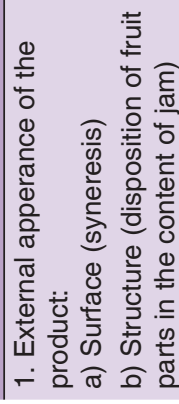

$\frac{1}{0}$
0
0 
germs and flax seeds and resulted from color and taste deterioration due to storage.

\section{CONCLUSIONS}

The quality of a product is the main indicator influencing consumer choice. The combination of sensory evaluation and the measurement of texture and color parameters allows for more accurate assessment of the quality of jams, which are popular fruit products. However, in conventional jam, the level of sugar is high, while the content of fruit is low. Therefore, low-sugar jams may be a good alternative to such products, because they have a higher proportion of fruits and can be produced using sucrose substitutes, for example, steviol glycoside, which reduce the caloric value of such products. The enrichment of strawberry jam with plant ingredients of high nutritive value or prebiotic effect (black chokeberry, elderberry, Japanese quince, and inulin) allowed for the preparation of a new product with interesting sensory features. In contrast, the addition of flax seeds and wheat germs had less beneficial effect, especially on the color and flavor, and increased the hardness of jams. Strawberry jam should, however, be chill-stored, since such conditions guarantee better texture and color stability in the product.

\section{ACKNOWLEDGEMENTS}

This research was financed by the Ministry of Science and Higher Education of the Republic of Poland.

\section{Author contributions}

A.K. Designed research, analyzed the results, prepared and revised the manuscript. A.B. performed the experiments, analyzed the results, and prepared the manuscript. J.K. Performed texture analysis and analyzed the results.

\section{REFERENCES}

Alves de Oliveira, E. N., D. da Costa Santos, J. P. Gomes, A. P. T. Rocha and W. P. da Silva. 2015. Physicochemical stability of diet Umbu-Caja jams stored under ambient conditions. J. Food Process. Preserv. 39: 70-79.

Barrett, D. M., J. C. Beaulieu and R. Shewfelt. 2010. Color, flavor, texture, and nutritional quality of fresh-cut fruits and vegetables: Desirable levels, instrumental and sensory measurement, and the effects of processing. Crit. Rev. Food Sci. Nutr. 50: 369-389.

Basu, S. and U. S. Shivhare. 2010. Rheological, textural, microstructural and sensory properties of Mango jam. J. Food Eng. 100: 357-365.

Besbes, S., L. Drira, C. Blecker, C. Deroanne and H. Attia. 2009. Adding value to hard date (Phoenix dactylifera L.): Compositional, functional and sensory characteristics of Date jam. Food Chem. 112: 406-411.

Brennan, C. S. and C. M. Tudorica. 2008. Carbohydrate-based fat replacers in the modification of the rheological, textural and sensory quality of yoghurt: Comparative study of the utilization of barley beta-glucan, guar gum and inulin. Int. J. Food Sci. Tech. 43: 824-833.

Bursać, D., N. Vahčić, B. Levaj, V. Dragović-Uzelac and A. Biško. 2007. The influence of cultivar on sensory profiles of fresh and processed strawberry fruits grown in croatia. Flavour Fragr. J. 22: 512-520.

Byamukama, R., B. T. Kiremire, $\varnothing$. M. Andersen and A. Steigen. 2005. Anthocyanins from fruits of Rubus pinnatus and Rubus rigidus. J. Food Compos. Anal. 18: 599-605.

CIE. 2004. Colorimetry. $3^{\text {rd }}$ ed. Commission Internationale de 'Eclairage, Vienna, Austria.

de Ancos, B., E. Gonzalez and M. P. Cano. 1999. Differentiation of raspberry varieties according to anthocyanin composition. Z. Lebensm. Unters. F. A. 208: 33-38.

EU. 2001. Council Directive 2001/113/EC of 20 December 2001 Relating to Fruit Jams, Jellies and Marmalades and Sweetened Chestnut Purée Intended for Human Consumption, OJ L10/67.

EU. 2011. Commission Regulation (EU) No 1131/2011 of 11 November 2011 Amending Annex II to Regulation (EC) No 1333/2008 of the European Parliament and of the Council with Regard to Steviol Glycosides, OJ L295/205.

Gao, X., T. Yu, Z. Zhang, J. Xu and X. Fu. 2011. Rheological and sensory properties of four kinds of jams. J. Stored Prod. Postharvest Res. 2: 227-234.

García-Martínez, E., G. Ruiz-Diaz, J. Martínez-Monzó, M. M. Camacho, N. Martínez-Navarrete and A. Chiralt. 2002. Jam manufacture with osmodehydrated fruit. Food Res. Int. 35: 301-306.

García-Viguera, C., P. Zafrilla, F. Romero, P. Abellán, F. Artés and F. A. Tomás-Barberán. 1999. Color stability of Strawberry jam as affected by cultivar and storage temperature. J. Food Sci. 64: 243-247.

Genovese, D. B., A. Ye and H. Singh. 2010. High methoxyl pectin/ apple particles composite gels: Effect of particle size and particle concentration on mechanical properties and gel structure. J. Texture Stud. 41: 171-189.

Grigelmo-Miguel, N. and O. Martín-Belloso. 1999. Influence of fruit dietary fibre addition on physical and sensorial properties of Strawberry jams. J. Food Eng. 41: 13-21.

Halat, M. S., C. A. Reitmeier, F. Takeda and D. L. Peterson. 1997. Sensory evaluation of jams made from three eastern Thornless and Marion blackberries. J. Food Qual. 20: 177-188.

ISO. 1998a. Sensory Analysis-Methodology-General Guidance, International Organization for Standardization, Geneva, Switzerland.

ISO. 1998b. Sensory Analysis-Methodology-Method of Investigating Sensitivity of Taste, International Organization for Standardization, Geneva, Switzerland.

Javanmard, M., N. L. Chin, S. H. Mirhosseini and J. Endan. 2012. Characteristics of gelling agent substituted fruit jam: Studies on the textural, optical, physicochemical and sensory properties. Int. J. Food Sci. Technol. 47: 1808-1818.

Kirca, A., M. Özkan and B. Cemeroğlu. 2007. Storage stability of Strawberry jam color enhanced with black carrot juice concentrate. J. Food Process. Preserv. 31: 531-545.

Kmiecik, W., Z. Lisiewska and G. Jaworska. 2001. Effect of aronia berry honey syrup used for sweetening jams on their quality. Nahrung. 45: 273-279.

Kopjar, M., V. Piližota, N. N. Tiban, D. Šubarić, J. Babić, D. Ačkar and M. Sajdl. 2009. Strawberry jams: Influence of different pectins 
on colour and textural properties. Czech J. Food Sci. 27: 20-28.

Kucharska, A., K. Kowalczyk, A. Nawirska-Olszańska and A. SokółŁętowska. 2010. Wpływ dodatku aronii, truskawek i malin na skład fizykochemiczny przecieru dereniowego. Żywność Nauka Technol. Jakość. 71: 95-106.

Levaj, B., D. B. Kovačević, M. Bituh and V. Dragović-Uzelac. 2012. Influence of jam processing upon the contents of phenolics and antioxidant capacity in strawberry fruit (Fragaria ananassa $x$ Duch.). Croat. J. Food Technol. Biotechnol. Nutr. 7: 18-22.

Lin, S., W. Chi, J. Hu, Q. Pan, B. Zheng and S. Zeng. 2017. Sensory and nutritional properties of Chinese olive pomace based high fibre biscuit. Emir. J. Food Agric. 29: 495-501.

Matsoukis, A., D. Gasparatos and A. Chronopoulou-Sereli. 2015. Mepiquat chloride and shading effects on specific leaf area and $\mathrm{K}, \mathrm{P}, \mathrm{Ca}, \mathrm{Fe}$ and Mn content of Lantana camara L. Emir. J. Food Agric. 27: 122-126.

Meyer, D., S. Bayarri, A. Tárrega and E. Costell. 2011. Inulin as texture modifier in dairy products. Food Hydrocoll. 25: 1881-1890.

Mokrzycki, W. S. and M. Tatol. 2011. Colour difference $\Delta \mathrm{E}$-a survey. Mach. Graph. Vision. 20: 383-411.

Ngo, T., R. E. Wrolstad and Y. Zhao. 2007. Color quality of Oregon strawberries-impact of genotype, composition, and processing. J. Food Sci. 72: 25-32

Ochoa, M. R., A. G. Kesseler, M. B. Vullioud and J. E. Lozano. 1999. Physical and chemical characteristics of raspberry pulp: Storage effect on composition and color. LWT Food Sci. Technol. 32: 149-153.

Patras, A., N. P. Brunton, B. K. Tiwari and F. Butler. 2011. Stability and degradation kinetics of bioactive compounds and colour in strawberry jam during storage. Food Bioprocess Technol. 4: 1245-1252.

Peressini, D. and A. Sensidoni. 2009. Effect of soluble dietary fibre addition on rheological and breadmaking properties of wheat doughs. J. Cereal Sci. 49: 190-201.

Rababah, T. M., M. H. Al-u'datt, M. A. Al-Mahasneh, H. Feng A. M. Alothman, A. Almajwal, W. Yang, I. Kilani, M. N. Alhamad, K. Ereifej and M. Abu-Darwish. 2011. Effect of storage on the physicochemical properties, total phenolic, anthocyanin, and antioxidant capacity of strawberry jam. J. Food Agric. Environ. 9: 101-105.

Rogowska, A. M. 2015. Synaesthesia and Individual Differences. $1^{\text {st }}$ ed. Cambridge University Press, Cambridge, UK.

Šavikin, K., G. Zdunić, T. Janković, S. Tasić, N. Menković, T. Stević and B. Đorđević. 2009. Phenolic content and radical scavenging capacity of berries and related jams from certificated area in Serbia. Plant Foods Hum. Nutr. 64: 212-217.

Suutarinen, J., K. Honkapää, R. L. Heiniö, K. Autio and M. Mokkila. 2000. The effect of different pre-freezing treatments on the structure of strawberries before and after jam making. LWT Food Sci. Technol. 33: 188-201.

Tárrega, A. and E. Costell. 2006. Effect of inulin addition on rheological and sensory properties of fat-free starch-based dairy desserts. Int. Dairy J. 16: 1104-1112.

Wargovich, M. J., J. Morris, V. Moseley, R. Weber and D. H. Byrne. 2012. Developing fruit cultivars with enhanced health properties In: M. L. Badenes. and D. H. Byrne (Eds.), Fruit Breeding, Springer US, Boston, MA, pp. 37-68.

Wicklund, T., H. J. Rosenfeld, B. K. Martinsen, M. W. Sundfør, P. Lea, T. Bruun, R. Blomhoff and K. Haffner. 2005. Antioxidant capacity and colour of strawberry jam as influenced by cultivar and storage conditions. LWT Food Sci. Technol. 38: 387-391.

Žitňanová, I., S. Ranostajová, H. Sobotová, D. Demelová, I. Pecháň and Z. Duračková. 2006. Anti-oxidative activity of selected fruits and vegetables. Biologia. 61: 279-284 